\title{
Student preference for alternative modes of transport at the University of Pretoria, South Africa
}

\author{
J. L. du Toit \\ Department of Town and Regional Planning, \\ University of Pretoria, South Africa
}

\begin{abstract}
The University of Pretoria is the largest contact university in South Africa with more than 45,000 contact students. A significant increase in students over the last decade has contributed to severe parking shortages on and around the main campus. Consequently, the University has been considering four alternative modes of transport to reduce car usage, including (1) pedestrian routes, (2) bicycle routes, (3) a hop-on/hop-off campus bus, and (4) park-and-ride. A campus-wide voluntary online survey was conducted to determine students' preference for each mode, including a fifth one - a fare-free bus. The latter is based on 'Unlimited Access', a concept that has been successfully implemented at numerous universities in the US, whereby the university pays the transit agency for student ridership. A total of 755 students responded to the survey while responses were weighted to represent the actual student population. The survey showed the fare-free bus to be most preferred, even for car-users, suggesting that the University should rather, or at least also, consider an intervention similar to Unlimited Access. The paper examines possible reasons why the fare-free bus was most preferred, and argues the importance of consulting best-practice and student preference surveys in campus planning interventions.
\end{abstract}

Keywords: alternative modes of transport, unlimited access, fare-free transit, campus planning, preference surveys. 


\section{Introduction}

Universities present unique transportation challenges due to high parking demand and travel patterns that do not necessarily correspond with typical peak flows. Transportation on campuses has therefore been covered in numerous studies, particularly with regard to students as the largest stakeholder group on campus. While some focus on planning aspects (e.g., see Balsas [1]), many cite Ajzen's [2] Theory of Planned Behaviour and appear to focus on behavioural aspects, such as travelling intensions (e.g., see Kerr et al. [3]), commuting habits (e.g., see Shannon et al. [4]), and preference for alternative modes of transport (e.g., see Zhou [5]). An alternative mode that appears to be quite popular in the US is fare-free transit, based on a concept known as 'Unlimited Access'.

'Unlimited Access' involves an arrangement whereby a university pays a local transit agency an annual lump sum based on expected student or staff ridership. The university typically utilises funds it would otherwise have spent on providing and maintaining parking facilities. Students or staff can then use fare-free transit on selected routes around the campus by simply presenting or swiping their university ID cards. Unlimited Access has been successfully implemented at numerous universities in the US under various names, such as UPass, ClassPass and SuperTicket, with only one programme failure reported so far. Some of the advantages for the university include reduced parking demand and better recruitment and retaining of students, while the transit agency is able to increase ridership and revenue and improve its overall service. For students the potential benefits include increased mobility and affordability to attend university, as well as fairness - the university subsidises all students, not just those with a car by providing parking below market rates (Brown et al. [6]; Brown et al. [7]; Zolnik [8]).

This paper focuses the preference of students at the University of Pretoria, South Africa, for alternative modes of transport, including a mode such as farefree transit, or a 'fare-free bus' as it was termed in this study. The University urgently needs campus planning interventions that could bring about greater modal change among students, while the study reported here is intended to help inform such interventions.

\section{Background and research aim}

The University of Pretoria is probably the most comprehensive university in South Africa with nine faculties and a business school. Currently the University has more than 600 buildings spread over approximately 1 200ha of land across six campuses (University of Pretoria [9]). The main campus, which is the focus of this study, is located in the suburb of Hatfield east of central Pretoria, the administrative and R\&D capital of South Africa. Although the campus grew incrementally over time, it has long since comprised a kind of superblock that is completely fenced off from surrounding neighbourhoods with controlled access all around. Public roads that used to cut across campus have been closed off over the last two decades and integrated into the campus' built fabric. Consequently, 
most students who travel to campus by car have to find kerbside parking outside the perimeter fencing of the campus, much to their frustration with ad hoc fines or having to tip self-appointed 'car guards' to reduce the threat of car theft. Although the University recently constructed a multi-storey paid-parking facility on campus, a significant increase in students over the last decade has contributed to severe parking shortages on and around campus. According to the University's Bureau for Institutional Research and Planning, the total number of contact students increased from about 28,000 in the year 2000 to about 44,000 in 2010. Total headcount currently stands at over 45,000, making the University of Pretoria by far the largest contact university in the country. Moreover, the University's Strategic Plan projects an estimated total enrolment of 55,000 students by the year 2025 (University of Pretoria [10]). This further increase, coupled with a growing middle class that would include car-owning students, highlights the importance of planning for alternative modes of transport to-andfrom the main campus.

The University's Facilities Management Department has indeed been considering four alternative modes of transport to reduce car usage, including (1) pedestrian routes, (2) bicycle routes, (3) a hop-on/hop-off campus bus, and (4) park-and-ride. Although some attention has been paid to pedestrian and bicycle routes as part of campus planning, these are certainly not yet identifiable nor have they been planned or implemented as fully integrated modes to extend beyond the campus. The 'hop-on/hop-off campus bus' was also merely an idea at the time of the study, and refers to a bus that would operate a circular route on campus. Only the park-and-ride had been implemented at the time of the study, which involves busses that operate between the main campus and the university sports-grounds, including one of the smaller satellite campuses where there is a surplus of parking.

The aim of this study was to examine students' preference for these four alternative modes of transport given the urgency of the parking problem and, hence, assess the possible impact these four modes may have on reducing car usage. However, the research team felt it necessary to also test the concept of 'Unlimited Access', which was conceptualised and described as a 'fare-free bus' for the purpose of this study. From a planning perspective, and given the particular context at the University of Pretoria, the research team hypothesised that a fare-free bus, if based on an arrangement similar to Unlimited Access, will probably be preferred to the four modes currently considered by the University. If this was the case, it would suggest that Unlimited Access, or fare-free transit, may actually be more effective in reducing car usage on and around the campus.

\section{Research design and methods}

A campus-wide voluntary online survey was conducted on the University's student portal during the second half of 2010. A questionnaire was designed that would first capture information on students' travel behaviour to-and-from the main campus, including current place of residence while studying, and current mode of transport to-and-from the main campus. The questionnaire then 
provided a brief description of each of the five alternative modes, followed by 10 four-point Likert-scales that required students to rate the likelihood of using each mode to travel to-and-from the main campus both in addition to and instead of their current mode (i.e., two scales times five different modes), with ' 1 ' denoting 'never', '2' - 'occasionally', '3' - 'regularly' and '4' - 'always'. An open-ended question was also provided following the rating of each mode asking students what they thought the University could do to increase their use of that particular mode. After ethical clearance was obtained from the Faculty, the University's division for Education Innovation developed a web-based version of the questionnaire for piloting. The pilot revealed no serious problems and the questionnaire went live on the student portal together with a cover note explaining the purpose of the survey and an informed consent that students had to tick to access the questionnaire.

Within about a month a total of 755 students responded after which the survey was closed following a noticeable decline in responses. Data were imported into SPSS (Statistical Package for the Social Sciences) for analysis. The University's Bureau for Institutional Research and Planning then provided a student headcount for the year disaggregated into strata based on sex, race, and level of study (under- vs. postgraduate). Because each of the 755 responses were logged with a student number, it was possible to allocate each response to a stratum and calculate weights in SPSS for each stratum based on a particular stratum's response rate. Thus, each response within a particular stratum was weighted during data analysis to account for unequal response rates across strata, thereby representing the student population more accurately in terms of sex, race and level of study. All figures in subsequent tables are therefore weighted figures.

\section{Findings}

Findings are presented in terms of students' (1) current mode of transport to-andfrom the main campus, (2) preference ratings for alternative modes in addition to current modes, and (3) preference ratings for alternative modes instead of current modes. Table 1 shows a percentage breakdown of current mode of transport toand-from the main campus ranked in order of the most to least used mode in terms of combined percentages. Students could have indicated multiple modes of transport, while results are disaggregated by place of residence while studying.

Table 1 shows that more than half (about 55\% or 34,000 in total) of all trips generated to-and-from the main campus involve individual private car trips, making it by far the dominant mode of transport. If being dropped off and lift clubs/car pools are included here, the reliance on private car to travel to campus is even higher. These levels of private car usage can be considered very high for a student population in a developing country, yet it merely reflects a country known for high levels of car-dependence coupled with bad public transport. Formal public transport, notably bus and train, make up only $6.5 \%$ of all trips, while mini-bus taxis, an informal industry servicing former Black townships mostly, make up about 4\%. Train usage may have increased since 2011 with the 
opening of the Gautrain, a passenger rail system linking Johannesburg with Pretoria and terminating in Hatfield near the main campus. Although walking comprised the second biggest mode (about 16\%), a large portion of it does not necessarily involve walking between home and campus, but between home or campus and public transport stops.

Table 1: $\quad$ Current mode of transport to-and-from the main campus.

\begin{tabular}{|c|c|c|c|c|c|c|}
\hline \multirow{3}{*}{$\begin{array}{l}\text { Current mode of } \\
\text { transport to-and- } \\
\text { from the main } \\
\text { campus }\end{array}$} & \multicolumn{6}{|c|}{ Place of residence while studying } \\
\hline & \multicolumn{2}{|c|}{$\begin{array}{l}\text { Within a } 5 \mathrm{~km} \text { radius } \\
\text { from the main campus }\end{array}$} & \multicolumn{2}{|c|}{$\begin{array}{c}\text { Outside a } 5 \mathrm{~km} \text { radius } \\
\text { from the main campus }\end{array}$} & \multicolumn{2}{|c|}{ Combined } \\
\hline & Count & $\%$ & Count & $\%$ & Count & $\%$ \\
\hline Private car & 11,357 & 37.7 & 22,453 & 71.1 & 33,811 & 54.8 \\
\hline Walking & 9,322 & 30.9 & 679 & 2.2 & 10,002 & 16.2 \\
\hline Dropped off & 1,302 & 4.3 & 2,091 & 6.6 & 3,393 & 5.5 \\
\hline Bus & 1,933 & 6.4 & 1,344 & 4.3 & 3,276 & 5.3 \\
\hline Park-and-ride & 2,260 & 7.5 & 638 & 2.0 & 2,898 & 4.7 \\
\hline Mini-bus taxi & 1,455 & 4.8 & 1,073 & 3.4 & 2,528 & 4.1 \\
\hline Lift club/car pool & 552 & 1.8 & 1,767 & 5.6 & 2,319 & 3.8 \\
\hline Bicycle & 1,170 & 3.9 & 321 & 1.0 & 1,491 & 2.4 \\
\hline Motorcycle/scooter & 538 & 1.8 & 753 & 2.4 & 1,291 & 2.1 \\
\hline Train & 260 & 0.9 & 461 & 1.5 & 721 & 1.2 \\
\hline Total & 30,149 & 100.0 & 31,580 & 100.0 & 61,729 & 100.0 \\
\hline
\end{tabular}

What is critical, however, is that more than 11,000 students use a private car, but reside within a $5 \mathrm{~km}$ radius from the main campus, an area that would include all the University residences, the high-density suburbs of Sunnyside and Arcadia, and most student communes. Yet, these students can probably be expected to show higher levels of public transport use, including of lift clubs/car pools, and lighter forms of travel such as bicycles, motorcycles and scooters. However, while a mere $4 \%$ of trips by these students comprise bicycles, a larger proportion of trips by students who reside outside a $5 \mathrm{~km}$ radius comprise motorcycles and scooters $(2.4 \%)$, as opposed to trips by those who reside inside a $5 \mathrm{~km}$ radius (1.8\%). The necessity and likewise potential to reduce car usage, especially among students who reside within a 5km radius from the main campus, is clearly evident. It is in this regard that student preference for alternative modes of transport, especially within a $5 \mathrm{~km}$ radius from the main campus, becomes important.

Table 2 shows mean preference ratings for alternative modes of transport in addition to current modes by students who reside within a $5 \mathrm{~km}$ radius from the main campus, disaggregated by car-users vs. non car-users. The different modes are ranked in order of most to least preferred in terms of the highest to lowest combined mean. Since a four-point Likert-scale was used ranging from 1-4, ratings lower than 2.5 denote relative low levels of preference, while ratings higher than 2.5 denote relative high levels of preference.

Clearly, students preferred to use a fare-free bus in addition to their current mode of transport more than any other alternative mode (combined mean $=3.1$ ), although the standard deviation (1.5) suggests quite a variation in responses. Thus, students tended to prefer to use a fare-free bus either 'never' or 'always' in 
Table 2: $\quad$ Preference ratings for alternative modes of transport in addition to current modes.

\begin{tabular}{|c|c|c|c|c|c|c|c|}
\hline \multirow{3}{*}{$\begin{array}{l}\text { Alternative modes } \\
\text { of transport }\end{array}$} & \multicolumn{6}{|c|}{$\begin{array}{l}\text { Students who reside within a } 5 \mathrm{~km} \text { radius from the main campus: } \\
\text { car-users vs. non car-users }\end{array}$} & \multirow{3}{*}{$\begin{array}{c}\text { t-Test } \\
p \text {-value }\end{array}$} \\
\hline & \multicolumn{2}{|c|}{ Car-users } & \multicolumn{2}{|c|}{ Non car-users } & \multicolumn{2}{|c|}{ Combined } & \\
\hline & Mean & $\begin{array}{l}\text { Std. } \\
\text { Dev. }\end{array}$ & Mean & $\begin{array}{l}\text { Std. } \\
\text { Dev. }\end{array}$ & Mean & $\begin{array}{l}\text { Std. } \\
\text { Dev. }\end{array}$ & \\
\hline Fare-free bus & 3.1 & 1.4 & 3.1 & 1.6 & 3.1 & 1.5 & .99 \\
\hline Pedestrian routes & 2.5 & 1.1 & 3.5 & 1.3 & 2.9 & 1.3 & $* .00$ \\
\hline $\begin{array}{l}\text { Hop-on/hop-off } \\
\text { campus bus }\end{array}$ & 2.6 & 1.4 & 2.7 & 1.4 & 2.6 & 1.4 & .82 \\
\hline Park-and-ride & 2.3 & 1.3 & 2.1 & 1.2 & 2.2 & 1.3 & .25 \\
\hline Bicycle routes & 1.7 & 1.1 & 1.7 & 1.3 & 1.7 & 1.2 & .68 \\
\hline
\end{tabular}

addition to their current mode. Only two other modes yielded relatively high levels of preference, i.e., pedestrian routes and a hop-on/hop-of campus bus, while two modes yielded relatively low levels of preference, i.e., park-and-ride and bicycle routes, the latter being the least preferred. Inconvenience, caroriented road networks, and concerns over safety - both in terms of crime and accidents, are likely to deter students from cycling, including the possibility of bicycle theft and facing intolerant drivers (e.g., see Balsas [1]).

There were no statistically significant differences between the preference ratings of car-users vs. non car-users, except for pedestrian routes, which appeared to be preferred much more by non car-users $(p=.00)$. While non-car users preferred pedestrian routes more than any other mode, car-users, interestingly, preferred a fare-free bus more than any other mode, even above park-and-ride, which is actually intended for car-users. Considering the estimated 11,000 students who live within a $5 \mathrm{~km}$ radius from the main campus and use a car to travel to-and-from campus, what is of critical interest here is that a fare-free bus may therefore help to significantly reduce car usage more so than any other mode, in so far as students would be willing to use such a mode in addition to their current mode. Table 3 similarly shows mean preference ratings for alternative modes of transport instead of current modes.

When asked about the extent to which students would use any of the five alternative modes instead of their current mode, the same order of preference emerged, with a fare-free bus again emerging as the most preferred mode overall (mean rating $=3.1$ ) and bicycle routes as the least preferred (mean rating $=1.6$ ). Both car-users and non-car users again expressed the same level of preference for a fare-free bus (mean ratings $=3.1$ ), while non car-users' preference for pedestrian routes dropped from a rating of 3.5 (in addition to current mode) to 3.1 (instead of current mode). Thus, non car-users now also prefer a fare-free bus more so than any other mode apart from pedestrian routes.

Table 3 therefore reiterates the finding above that a fare-free bus may help to significantly reduce car usage, this time in so far as students would be willing to 
Table 3: $\quad$ Preference ratings for alternative modes of transport instead of current modes.

\begin{tabular}{|c|c|c|c|c|c|c|c|}
\hline \multirow{3}{*}{$\begin{array}{c}\text { Alternative modes } \\
\text { of transport }\end{array}$} & \multicolumn{6}{|c|}{$\begin{array}{l}\text { Students who reside within a } 5 \mathrm{~km} \text { radius from the main campus: } \\
\text { car-users vs. non car-users }\end{array}$} & \multirow{3}{*}{$\begin{array}{c}\text { t-Test } \\
p \text {-value }\end{array}$} \\
\hline & \multicolumn{2}{|c|}{ Car-users } & \multicolumn{2}{|c|}{ Non car-users } & \multicolumn{2}{|c|}{ Combined } & \\
\hline & Mean & $\begin{array}{l}\text { Std. } \\
\text { Dev. }\end{array}$ & Mean & $\begin{array}{l}\text { Std. } \\
\text { Dev. }\end{array}$ & Mean & $\begin{array}{l}\text { Std. } \\
\text { Dev. }\end{array}$ & \\
\hline Fare-free bus & 3.1 & 1.5 & 3.1 & 1.6 & 3.1 & 1.6 & .98 \\
\hline Pedestrian routes & 2.1 & 1.2 & 3.1 & 1.5 & 2.6 & 1.4 & $* .00$ \\
\hline $\begin{array}{l}\text { Hop-on/hop-off } \\
\text { campus bus }\end{array}$ & 2.4 & 1.3 & 2.7 & 1.5 & 2.5 & 1.4 & $* .02$ \\
\hline Park-and-ride & 2.2 & 1.4 & 2.2 & 1.3 & 2.2 & 1.3 & .61 \\
\hline Bicycle routes & 1.6 & 1.1 & 1.6 & 1.1 & 1.6 & 1.1 & .98 \\
\hline
\end{tabular}

use such a mode instead of their current mode. Again, preference ratings for a fare-free bus between car-users vs. non car-users were not statistically significant $(p=.98)$, meaning that a fare-free bus system may be targeted at both car-users and non car-users to increase ridership. The fact that car-users in a $5 \mathrm{~km}$ radius from the main campus in both instances showed relatively low preference for park-and-ride, suggests that students would rather struggle to find parking as close as possible to where they have to be if they are going to use their cars, or else substitute their cars for another mechanised form of transport, like a farefree bus, that might as well save them the difficulty of finding parking or changing modes at a park-and-ride facility.

While the benefits of a fare-free bus system for non car-users may be evident, the reasons why even car-users opted for this mode more than any other require further examination. A Chi-squared Automatic Interaction Detection (CHAID) was used to test which independent (predictor) variable had the strongest interaction with car-users' preference ratings for a fare-free bus within a $5 \mathrm{~km}$ radius from the main campus, both in addition to and instead of their current mode. Independent variables that were tested included (1) sex, (2) race, (3) level of study (i.e., under- vs. postgraduate), and (4) type of study (i.e., full- vs. part time). Preference ratings were recoded into nominal variables denoting 'never', 'occasionally/regularly', or 'always'. Statistical significance was calculated at the .05 level, while weights were scaled down to $n=755$ to avoid inflated chisquare values.

In terms of the preference for a fare-free bus in addition to current mode, 'race' emerged as the strongest predictor, with a significantly larger percentage of Black students (including Coloured and Indian students) (about 58\%) indicating that they would always use a fare-free bus as opposed to the percentage of White students (about 17\%), while a significantly larger percentage of White students (about 62\%) indicated that they would use it occasionally/regularly as opposed to the percentage of Black students (about 42\%) $\left(\chi^{2}(1, N=152)=29.535, p=.00\right)$. Consequently, no Black student 
indicated that they would never use it whereas about $21 \%$ of White students did though. Similarly, in terms of the preference for a fare-free bus instead of current mode, again, a significantly larger percentage of Black students (about 63\%) indicated that they would always use a fare-free bus as opposed to the percentage of White students (about 21\%), while a significantly larger percentage of White students (about 56\%) indicated that they would use it occasionally/regularly as opposed to the percentage of Black students (about 32\%) $\left(\chi^{2}(1, N=152)=\right.$ 23.134, $p=.00$ ).

Black students, many of whom are likely to be more familiar with public transport compared to their White counterparts, seem willing to exchange a costly car for a fare-free bus whilst being a student, whereas White students appear to be more attached to their cars, opting to use a fare-free bus occasionally or regularly, but not necessarily always. While parking shortages around campus may cause White students to realise the benefits of being car-free at times, being without a car per se is not likely to be an option if one can afford a car anyway, since having a car is convenient or even necessary in a country where public transport is otherwise still very bad. Responses to open-ended questions also suggest that students were less eager to share a fare-free bus with the public, citing 'crime and grime' as reasons. However, considering current demographic shifts at South African universities, the proportion of Black students at the University of Pretoria is likely to increase over time, which would probably lead to an even greater demand in future for a system such as Unlimited Access, thereby making such as system even more feasible than it current appears. Another reason why students preferred a fare-free bus more than any other alternative mode, apart from it being free, may include perceptions that it would be more convenient and safer than walking or cycling. Further research is necessary to confirm such possible reasons.

\section{Conclusion}

This paper focused on students' preference for alternative modes of transport, including (1) pedestrian routes, (2) bicycle routes, (3) a hop-on/hop-of campus bus, (4) park-and-ride and (5) a fare-free bus - the latter based on the concept of 'Unlimited Access'. Although the University are currently considering the first four only, a fare-free bus was most preferred, even by car-users, while bicycle routes were least preferred. This suggests that the University should rather, or at least also, consider an intervention similar to Unlimited Access to significantly reduce car usage and parking shortages on and around its main campus. The study thus highlighted the importance of preference surveys and consulting best practice in campus planning interventions. Although South African campuses face unique challenges, campus planners in South Africa can gain useful ideas from countries with similar car-oriented cities and cultures, especially in the US and Australia. Unlimited Access does however require a partnership with a local transit agency. In this case it would be the City of Tshwane Metropolitan Municipality, although the municipality's bus service is currently in dire straits. This presents a challenge for the University should it consider Unlimited Access, 
although such a partnership may actually help to improve the municipal bus service.

\section{References}

[1] Balsas, C.J.L., Sustainable transport planning on college campuses. Transport Policy, 10, pp. 35-49, 2003.

[2] Ajzen, I., The theory of planned behaviour. Organizational Behavior and Human Decision Process, 50, pp. 179-211, 1991.

[3] Kerr, A., Lennon, A. and Watson, B., The call of the road: factors predicting students' car travelling intentions and behaviour. Transportation, 37, pp. 1-13, 2010.

[4] Shannon, T., Giles-Corti, B., Pikora, T., Bulsara, M., Shilton, T. and Bull, F., Active commuting in a university setting: Assessing commuting habits and potential for modal change. Transport Policy, 13, pp. 240-253, 2006.

[5] Zhou, J., Sustainable commute in a car-dominant city: Factors affecting alternative mode choices among university students. Transportation Research Part A, 46, pp. 1013-1029, 2012.

[6] Brown, J., Hess, D.B. and Shoup, D., Unlimited Access. Transportation, 28, pp. 233-267, 2001.

[7] Brown, J., Hess, D.B. and Shoup, D., Fare-free public transit at universities: An evaluation. Journal of Planning Education and Research, 23, pp. 6982, 2003.

[8] Zolnik, E.J., Cost attribution in unlimited access transit programmes: Case study on the UConn Prepaid Fare Program failure. The Professional Geographer, 59(3), pp. 365-377, 2007.

[9] University of Pretoria, UP at a glance, http://web.up.ac.za/sitefiles/file/ publications/2012/afr/UP at_a glance(afr).pdf

[10] University of Pretoria, Strategic plan: The vision, mission and plan of the University for 2025, http://web.up.ac.za/sitefiles/file/publications/2012 /afr/strategiese_plan_2012.pdf 